\title{
A Contribuição do Método Montessori para o Desenvolvimento Cognitivo da Criança Portadora da Síndrome de Down
}

\author{
Maria da Piedade Resende da Costa \\ Maria Lúcia Lamoréa \\ Universidade Federal de São Carlos (UFSCar)
}

Investiga se princípios e material montessorianos poderiam ser utilizados com sucesso por crianças portadoras da síndrome de Down. Três crianças com esta síndrome foram expostas a seis tipos diferentes de atividades montessorianas, totalizando 60 sessões para cada participante: os comportamentos observados e registrados informaram sobre acertos e erros na execução das tarefas, ou seja, como cada criança resolveu o problema ao ser exposta ao material montessoriano. Conforme análise dos dados, cada criança demonstrou habilidade e criatividade no manuseio do material de acordo com o seu ritmo e repertório. Concluiu-se que os princípios e material montessorianos podem ser utilizados para o ensino da criança portadora da síndrome de Down.

Inúmeros estudos sobre o desenvolvimento e o desempenho de crianças com síndrome de Down, em situação escolar, podem ser encontrados na literatura especializada.

Em uma cuidadosa investigação realizada por Morss (1983) sobre o que determina o desenvolvimento cognitivo em crianças portadoras da síndrome de Down, comparado com o desenvolvimento que ocorre com crianças normais, foi observado que o retardo aparece em todos os aspectos deste desenvolvimento. 
Dois grupos de crianças foram estabelecidos para o estudo de Morss: um de crianças normais e outro com portadoras da síndrome de Down. O segundo grupo era constituído de oito crianças (seis meninas e dois meninos), com idade variando entre 12 e 22 meses. Essas crianças foram observadas e avaliadas, em oito sessões, com intervalos entre duas a três semanas.

O objetivo do estudo de Morss ( 1983) era investigar se o desenvolvimento cognitivo da criança com síndrome de Down, na sua essência, é igual ao que ocorre com a criança normal.

O grupo das crianças normais era formado por 26 crianças: 12 meninas e 14 meninos, com idade entre 9 e 21 meses, e eram avaliados de duas em duas semanas. Os experimentos foram realizados nos Departamentos de Psicologia das Universidades de Edinburgh e Glasgow. O experimento foi dividido em seis tarefas, formadas por três pares de itens. Cada par apresentava um certo nível de complexidade seguindo uma seqüência. As seis tarefas foram apresentadas em uma ordem plenamente balanceadas.

O desenvolvimento cognitivo, em crianças com síndrome de Down, não pode ser adequadamente descrito como sendo um desenvolvimento normal, porém mais lento (modelos piagetianos discordam do modelo em que se diz que o desenvolvimento cognitivo da criança portadora da síndrome de Down é mais lento). $\mathrm{O}$ desenvolvimento cognitivo difere qualitativamente, entre os dois grupos. Em termos de discussão, entre desenvolvimento normal e desenvolvimento diferenciado, o estudo fornece um suporte para essa aproximação.

Outro estudo que merece destaque foi o realizado por Casey, Jones, Kugler e Watkings (1988). Nesse trabalho, os pesquisadores separam dois grupos de crianças, na faixa etária entre 3 anos e 8 meses e 10 anos, sendo cada grupo constituído de 23 crianças. Um dos grupos freqüentava uma escola especial para crianças com dificuldade moderada de aprendizagem, e o outro, uma escola comum (jnainstrean).

As crianças que apresentavam dificuldades moderadas, durante dois anos, foram sistematicamente observadas e avaliadas em um ambiente físico preparado para recebê-las, com currículo e professores adequados para atendê-las. A cada seis meses, elas passavam pela mesma bateria de exercícios. 
Os pesquisadores, através desse estudo, monitoravam e avaliavam o desenvolvimento cognitivo e a aquisição acadêmica dessas crianças, que compreendiam as linhas de base.

O experimento durou dois anos, e durante esse período foram aplicados cinco testes (linha de base), no início, aos 6, 12, 18 e 24 meses, sendo que houve um monitoramento constante do progresso evolutivo durante os intervalos das unhas de base.

As crianças foram avaliadas pelo teste padrão de inteligência (Binet), testes para avaliar linguagem, habilidades de leitura e de expressão. Os testes utilizados durante as linhas de base foram: testes de compreensão de linguagem, teste de expressão de linguagem, escala de Reynell do desenvolvimento de linguagem, escala de fluencia verbal, escala de habilidade em escrita e aquisição de leitura.

No início dos testes, as meninas apresentaram melhores resultados em linguagem expressiva do que os meninos, porém, durante os dois anos, essas diferenças diminuíram, ou seja, havia pouca diferença entre as performances masculina e feminina na última linha de base.

No final dos testes, os dados mostraram que não houve um efeito significativo entre ambos os grupos, com relação ao sexo, interação entre os sexos, ou escalas, em qualquer uma das cinco fases da linha de base. Entretanto, houve uma significativa indicação, que as crianças do mainstrean obtiveram melhores escores, na fase cinco, que as crianças da escola assistida.

Foram analisadas as variações dos escores obtidos em idade mental, no início do estudo, o que mostrou não haver diferença entre as crianças dos dois grupos (homogeneização dos grupos, em relação à idade mental).

No progresso mostrado pelas crianças do mainstrean não se atribuía diferença entre os grupos depois da linha de base, mas somente a diferença de estágio significativa. As meninas foram melhores em expressão e linguagem que os meninos, mas essa diferença entre os sexos desapareceu após dois anos de estudo. No final, foi mostrado que as crianças do mainstrean obtiveram resultados superiores, se comparadas com o outro grupo. Elas tiveram um pequeno, mas significativo ganho, com relação a oportunidades verbais e compreensão de números. 
Outro trabalho a ser destacado é o de Alves (1987). Nesse trabalho o autor descreve um estudo exploratório das estratégias de crianças portadoras da síndrome de Down em tarefas relacionadas a etapas iniciais da aquisição de leitura e escrita. Descreve e analisa os resultados relacionados ao desempenho de duas crianças obtidos em três etapas: a) discriminar a extensão de estímulos visuais e sonoros; b) relacionar a extensão falada e escrita de palavras; e c) analisar silábicamente palavras ditadas. Concluiu que há diferença na zona proximal de desenvolvimento dessas crianças e das normais, no sentido de que as estratégias alcançadas com ajuda, pelas crianças portadoras da síndrome de Down, são semelhantes às apresentadas pelas normais "espontaneamente".

O estudo com crianças portadoras da síndrome de Down e o da aquisição em relação à matemática, realizado por Bird ( 1991 ), mostrou em suas conclusões que essas crianças não devem ter compreensão de processos de contagem, entretanto deve ficar claro que elas podem desenvolver a compreensão de tais princípios. O estudo evidencia, também, que essas crianças compreendem com maior facilidade por associação, assim resolvem problemas seguindo um modelo. Conclui ainda que é importante mostrar a essas crianças que numerais são somente sinais e que estes são apenas uma maneira de mostrar o princípio de contagem.

O estudo também concluiu que a menor capacidade de trabalhar com números por essas crianças é superada em um estágio mais avançado, necessitando ser introduzido gradativamente.

Outro trabalho importante sobre aquisições de crianças portadoras da síndrome de Down é o de Buckley (1992). Ele descreve que, através do uso de cartões ilustrados, a criança aprende primeiro as palavras, depois vai formando frases, e assim o seu vocabulário vai sendo ampliado, o que ocorre em etapas.

A diferença entre crianças normais e as portadoras da síndrome de Down expostas ao processo de leitura, conforme foi constatado através do estudo de Buckley (1992), pode ser assim resumida: crianças normais com cartões ilustrados ampliam o seu vocabulário, o agrupamento de palavras acelera a aprendizagem de leitura e ao formar frases a criança aprende corretamente gramática. Quanto as crianças com síndrome de Down não são simplesmente 
atrasadas em seu desenvolvimento, são também afetadas por um número específico de dificuldades na compreensão, como dificuldade no comando de diferentes áreas do desenvolvimento e com possibilidade de seguir caminhos diferentes em algumas áreas como a linguagem.

Buckley (1992) explica que as intervenções precisam ser baseadas na inteligência da criança especificamente, com relação a sua dificuldade de aprendizagem, considerando o que interfere no seu desenvolvimento. Essas intervenções precisam levar em conta como elas detêm as informações (memória, razão, entendimento).

Para este estudioso, o caminho seguido para a aquisição da leitura pela criança normal não é necessariamente o mesmo da criança com síndrome de Down. Como conclusão o autor explica que se pode ter rotas diferentes para se chegar ao mesmo ponto.

Um trabalho realizado sobre crianças portadoras da síndrome de Down, por Castro (1993), no Centro de Reabilitação de Pelotas, no Estado do Rio Grande do Sul, mostra as fases dos desenvolvimentos (cognitivo, afetivo, motor) que essas crianças vão ultrapassando, as dificuldades encontradas em cada uma delas e o que tudo isso acarreta, em termos educacionais, para essas crianças.

O estudo de Faria (1993), relacionado com a alfabetização de crianças portadoras da síndrome de Down, alunas de uma instituição especializada, foi desenvolvido através de um programa interdisciplinar, centrado nos interesses das crianças. Os resultados mostraram que as crianças apresentaram avanços relacionados com a leitura e a escrita, passando pelas mesmas fases que as crianças normais para tais aquisições. A diferença é que as crianças com síndrome de Down necessitam de um maior espaço de tempo para alcançar os mesmos resultados que as crianças normais.

Ainda, sobre estudos realizados a respeito do desenvolvimento cognitivo de crianças portadoras da síndrome de Down, que freqüentam uma instituição especializada, Ballaben, Faria e Monteiro (1994) realizaram uma investigação cujo objetivo foi criar um programa que auxiliasse a construção do pensamento lógico, visando ao alcance do estágio das operações concretas. Concluíram 
que o programa auxiliou a construção do pensamento lógico-matemático, inclusive, dando uma visão mais clara e detalhada do processo de desenvolvimento cognitivo destas crianças.

Os estudiosos sobre a aprendizagem dos portadores da síndrome de Down esclarecem que:

A posição ortodoxa defende que indivíduos com síndrome de Down não conseguem aproveitar muito do ensino acadêmico embora alguns aprendam a ler e a escrever... Muitas crianças recebem treinamento acadêmico tradicional em função do valor que os pais atribuem a isso. O resultado freqüente é um aumento do stress e a diminuição da auto-estima das crianças, sem nenhum ganho significativo na área educacional. (Gibson, apud Buckley, 1985,p.315).

Continuando, ainda sob esta ótica, Gibson explica que:

Alguns pais e professores dedicados obtiveram relativo sucesso com as crianças mais bem dotadas intelectualmente, talvez por terem intuitivamente adaptado os métodos de ensino às dificuldades das crianças.

Até o momento, o presente texto tratou sobre as possibilidades de aprendizagem do portador da síndrome de Down. Entretanto, como pode ser analisado, o processo do desenvolvimento cognitivo da criança portadora da síndrome de Down ainda se apresenta como um campo a ser explorado onde há necessidade de mais estudos.

A partir desta constatação, observou-se que os princípios e o método montessorianos poderiam ser aplicados a este tipo de criança com o objetivo de investigar a possibilidade da sua contribuição em relação ao aspecto do desenvolvimento cognitivo.

A concepção do método montessoriano surgiu durante o período em que Maria Montessori era estudante na Universidade de Roma, época em que já se interessava pelos problemas sociais que a cercavam (Montessori, 1957b; Lagoa, 1981; Pessoti, 1984). Após sua formatura, foi convidada para trabalhar na Clínica Psiquiátrica da própria universidade, local onde estavam internados adultos com distúrbios mentais e crianças mentalmente deficientes. Foi durante 
o contato com essas crianças que ela se interessou pela educação dos deficientes mentais (Montessori, 1957b).

Montessori ensinou a ler e a escrever algumas crianças deficientes, internas na clínica onde trabalhava, as quais, submetidas a exames em escolas públicas, alcançaram resultados semelhantes aos obtidos pelas crianças normais (Montessori, 1965; Lagoa, 1981).

Montessori (1957a, p.23) sentiu que esse sucesso ocorreu devido ao fato de elas serem atendidas pedagogicamente por uma via diferente da convencional. Isso porque acreditava na recuperação dessas crianças através da aplicação de um programa educacional adequado, crença esta que pode ser demonstrada na seguinte afirmação: "mas eu, contrariamente aos meus colegas, tive a intuição de que a questão dos deficientes fosse provavelmente pedagógica antes do que clínica".

A partir de então, começou a procurar material que tratasse do assunto: a educação de crianças deficientes mentais. Pouca coisa foi encontrada nesta investigação. Mas achou algo de grande importância: os trabalhos dos médicos franceses Itard e Séguin publicados respectivamente em 1807 e 1846. No trabalho de Itard foi descrito como ele desenvolveu um programa educacional com Victor, o menino de Aveyron. Quanto a Séguin, foi constatado que, em seu trabalho, ele escreveu um programa educacional para deficientes mentais (Montessori, 1965; Lagoa, 1981 ; Pessotti, 1984).

Montessori, para ter acesso aos trabalhos desses médicos, traduziu-os para o italiano e simultaneamente foi vivenciando suas próprias experiências educacionais. Ela acreditava que, com uma nova educação, seria possível melhorar o nível de aquisição das crianças deficientes mentais e baseando-se nessas idéias, funda e dirige de 1899 a 1901 a Escola Orto frénica, em Roma (Montessori, 1957b, 1965; Lagoa, 1981).

A experiência vivida por Montessori foi o alicerce de toda a sua vasta obra.

A educação, para a autora, é entendida como um auxílio à vida, ou seja, formada de conteúdo útil para o cotidiano, inserida no contexto onde a criança vive. Ela criou uma educação que engloba o biológico, o mental, o social e o 
psicológico. Desta forma, visa ao desenvolvimento do ser humano como um todo, para formar homens e mulheres preparados para a vida (Montessori, 1957b, 1965,1987; Lagoa, 1981).

Em 1907, Montessori começou a colocar em prática com crianças normais as experiências desenvolvidas com as deficientes mentais. Isso ocorreu na Casa Dei Bambini, escola que fundou nessa ocasião, em Roma. Por causa dessa adaptação - um método concebido para ser utilizado na alfabetização de crianças que apresentavam condutas anormais, transposto para as normais -recebeu críticas, cujo conteúdo era fazer generalizações indevidas (Montessori, 1957b; Lagoa, 1981).

Estudiosos sobre o método montessoriano, entre eles Lagoa (1981), defendem esta transposição. Segundo esse autor, mediante o seu trabalho prático, Montessori provou que o método adotado para a educação de crianças mentalmente débeis faz com que as crianças normais extraiam melhor a sua essência que as crianças comprometidas mentalmente, o que contribuiu para um desenvolvimento surpreendente das mesmas.

Essas crianças normais, da Casa Dei Bambini, com idade entre 3 e 7 anos, moravam em um conjunto residencial, sendo atendidas no próprio bairro. Em um relato sobre esse trabalho, Montessori ( 1965, p.38-39) expõe que esses alunos, devido a movimentos musculares descoordenados, apresentavam um caminhar inseguro, dificuldades para executar tarefas do cotidiano, defeitos de linguagem infantil características próprias de crianças que não tinham um acompanhamento pedagógico, além de um ambiente social carente de melhores recursos.

Consciente desse contexto, Montessori $(1987$, p. 100) relatou que atuou observando cada criança, comparando-as individualmente em cada fase de seu desenvolvimento para identificar as mudanças apresentadas que foram evidentes: elas foram se tomando mais sociáveis, interessadas e participantes das atividades, chegando a surpreender a professora quando apresentavam um trabalho ou uma pergunta interessante. Isso revela o que ela chama de descoberta. Aqui é importante destacar suas próprias palavras: "este é o quadro da psique da criança normal: primeiro ela absorve o mundo e depois o analisa". 
Em suas investigações, Montessori $(1965,1987)$ observou que as diferenças culturais não alteravam a essência que existe em cada criança, ou seja, o seu impulso para a vida, para a descoberta, para o desenvolvimento do ser como um todo. Observou, ainda, a alegria contagiante dessas crianças ao demonstrarem umas às outras o que são capazes de fazer por si sós, o apego à natureza e o desejo de contribuir para conservá-la eram semelhantes à de qualquer criança.

Através de suas constantes observações e registros dos comportamentos das crianças, começou a surgir o que foi denominado de método montessoriano. Este método compreende três etapas: $1^{\mathrm{a}}$ ) exercícios de vida prática; $2^{\mathrm{a}}$ ) exercícios para o desenvolvimento sensorial; e $3^{\mathrm{a}}$ ) exercícios para a aquisição de cultura (Montessori, 197- ; Lagoa, 1981).

No que se refere à etapa de exercícios da vida prática, constata-se que é constituída daqueles exercícios do cotidiano da criança tais como varrer o chão, lavar louças, consertar objetos, calçar sapatos, dobrar roupas, pentearse, etc, que visam aos movimentos adequados e à coordenação motora. Esses exercícios, de forma remota, vão preparando a criança para a aquisição da leitura, escrita e aritmética (Montessori, 1957a).

Para Montessori, o fato de a criança transportar e despejar água de um recipiente para outro sem derramar, molhar um vaso de plantas, varrer o chão dentro de um determinado ritmo, dobrar roupas, observando as divisões exatas, etc, está executando atividades que parecem banais, mas que contêm uma série de movimentos importantes (Montessori, 197-; Lagoa, 1981).

Os exercícios de vida prática, para Montessori, fazem a criança perceber e utilizar seu próprio corpo: pernas, braços, pés e especialmente mãos, que devem ser preparadas para a escrita e, também, sua mente: criando interesse e atenção pela atividade que está sendo desenvolvida no momento, o que a ajudará a desenvolver suas capacidades mentais para leitura, escrita e aritmética.

Em relação aos exercícios para o desenvolvimento sensorial, referentes à segunda etapa, Montessori descreve-os da seguinte forma: através dos materiais para o desenvolvimento sensorial, a criança vai percebendo as diferentes gradações de tons, cores, espessuras, etc. O exercício andar na linha, por 
exemplo, andar sobre o desenho de uma elipse traçada no chão, sem sair da linha, nem pisar no pé do colega é uma oportunidade para a criança adquirir equilíbrio (Montessori, 1965; Lagoa, 1981).

Neste mesmo exercício, andar na linha, ao ouvir a voz de comando, ela anda e pára, aprendendo a ouvir e seguir instruções. Ainda, a criança ouve uma música e, conforme o seu ritmo, anda mais depressa ou mais devagar. Aprende, também, a ficar em silêncio, para ouvir os sons do ambiente, por exemplo, o canto de um pássaro, o tique-taque do relógio, etc.

Finalmente, em relação à terceira etapa do método, nos exercícios para a aquisição de cultura, observa-se que já houve uma preparação remota através de exercícios de vida prática e de desenvolvimento sensorial cuja culminância ocorre nesta etapa. Agora a criança já está na fase de preparação direta, ou seja, a própria fase da aquisição de cultura (Montessori, 197-; Lagoa, 1981).

Para desenvolver os exercícios das três etapas citadas (vida prática, desenvolvimento sensorial e aquisição de cultura), é fundamental levar em consideração: a) o preparo do ambiente e b) o preparo adequado do professor.

Quanto ao preparo do ambiente, segundo Montessori, deve ser utilizado um local espaçoso, silencioso e em contato com a natureza (árvores, flores, gramado, etc). Os móveis devem ser acessíveis ao tamanho da criança: pequenas cadeiras, mesas, armários e utensílios de cozinha, ferramentas diversas, etc. e leves para serem mudadas de local pela criança com facilidade.

A sala de aula montessoriana não é aquela tradicional: carteiras enfileiradas, crianças quietas, sentadas, imóveis, professora em posição de destaque na frente da classe, vigiando os alunos. Ao contrário, as crianças têm liberdade para se comunicarem e se movimentarem na sala; geralmente elas sentam-se em tapetes no local que acharem mais adequado.

No que se refere ao preparo adequado do professor, conforme Montessori (1965), o professor precisa aprender a observar a criança, sem interferir, apenas quando for solicitado. Nas atitudes do professor, os castigos são abolidos e os elogios são discretamente emitidos. O professor deve deixar acessíveis os materiais necessários para cada fase em que seus alunos se encontram, pois as próprias crianças pegam, usam e depois espontaneamente os guardam no lugar. 
O trabalho é individualizado, respeitando o ritmo próprio de cada criança. O professor deve registrar os comportamentos de seus alunos. As comparações devem apenas ser feitas da seguinte forma: comparar a criança com ela mesma, em diferentes fases de seu aprendizado, ou seja, se ela está se tomando mais independente, mais atenta, mais observadora, etc.

O uso adequado do material é outro ponto básico no método montessoriano (Montessori, 197-; Lagoa, 1981). Algumas qualidades do material são fundamentais: devem ser atraentes e estéticas; as dificuldades são gradativas, apresentando um estímulo de cada vez como, por exemplo, as diferentes espessuras das lixas. Os materiais são modificáveis, isto é, são montados e desmontados podendo ser utilizados em várias fases do aprendizado; são proporcionais ao tamanho da criança e autocorretivos. A criança percebe que errou, porque as peças não se encaixam adequadamente, por exemplo: os cubos da escada marrom que vão do menor para o maior. Neste caso, o professor não deve interferir se a criança não os colocou adequadamente pois, em outra ocasião, ela estará apta a montá-los acertadamente.

Manipulando o material montessoriano, a criança concentra-se na atividade e trabalha em silêncio espontaneamente, executando a tarefa proposta de maneira agradável.

Com relação, ainda, à utilização adequada do material na fase de preparação direta para a escrita, a criança passa por uma etapa de treinamento de discriminação de forma, dimensão e tamanho das letras, através do encaixe de letras confeccionadas em ferro, letras em lixa e o alfabeto móvel.

As formas com as letras confeccionadas em ferro permitem vencer dificuldades como contornar o traçado das letras, até limitar comprimento e forma das mesmas, pois estas vão sendo encaixadas à medida que a criança as manuseia

No que diz respeito às letras em lixa, a criança vai passando os dedos sobre a superficie da forma da letra, associando o seu som e nome ao movimento que faz para grafá-la. 
Com o alfabeto móvel, a criança começa a formar algumas palavras.

Os materiais para a aprendizagem da leitura são: a) os cartões que contêm substantivos, os quais a criança deve emparelhar com a figura do objeto correspondente; e b) o jogo das ordens, que são cartões que contêm um verbo no imperativo. Estes cartões têm fundo branco medindo $14 \mathrm{x} 14 \mathrm{~cm}$, cujas letras e figuras devem ser acessíveis a crianças em fase de alfabetização.

Com relação ao material para o ensino da aritmética, a criança aprende facilmente conceitos de hierarquia, números, decimais, dimensões e quantidades, utilizando blocos (cubos), prismas (barras), cilindros coloridos, todos contendo dez elementos.

Após estas considerações sobre o desenvolvimento e o desempenho de crianças com síndrome de Down e o método montessoriano, a seguir, será relatado um estudo realizado sobre o método montessoriano para o ensino de crianças portadoras da síndrome de Down.

Participaram do referido estudo três crianças portadoras da síndrome de Down (um menino e duas meninas), na faixa etária entre três e sete anos, alunos de uma classe especial de uma escola da rede municipal de ensino de Araraquara, Estado de São Paulo.

As sessões para a coleta de dados foram realizadas em uma sala da escola, medindo 12 metros quadrados. E uma sala com iluminação natural, possuindo um vitrô que dá vistas para o exterior do prédio e uma porta que sai para o corredor interno. Quanto ao mobiliário, possui uma estante, uma mesinha e duas cadeirinhas de madeira, um arquivo e um armário de aço. Ainda possui uma pia.

Para fins de coleta de dados, o experimentador e a criança, em uma relação de um para um, permaneciam durante a sessão no espaço físico anteriormente descrito.

A criança, conforme o método montessoriano, tinha a liberdade para se movimentar, falar e manusear os materiais existentes. Ela podia se aproximar ou se distanciar do experimentador, solicitar informações, etc. 
O experimentador, por sua vez, procurava anotar, de forma abreviada, os comportamentos observados, sem interferir nas atitudes da criança.

Quanto ao equipamento, foram utilizados um toca-fitas Broksonic de procedência chinesa e uma máquina fotográfica Yashica.

Em relação ao procedimento, as crianças portadoras da síndrome de Down foram escolhidas porque atendiam ao critério para a escolha: a assiduidade.

Para a coleta de dados, no contato inicial entre a experimentadora e as crianças, foi realizada uma atividade montessoriana. A atividade escolhida foi despejar água de uma vasilha para outra, como piloto para a criança ser observada.

Neste piloto foi experimentado o tipo de registro para verificar qual seria o mais adequado. Constatou-se que o registro contínuo se aplicaria melhor às circunstâncias do estudo.

O registro do desempenho dos alunos foi realizado de forma abreviada (palavras-chaves), pela pesquisadora, durante as sessões. Entretanto, logo após o decorrer da sessão, a pesquisadora complementava a redação de forma mais detalhada sobre as observações realizadas. Esta decisão foi tomada após a realização do piloto, porque se chegou à conclusão de que se a pesquisadora permanecesse o tempo integral da sessão anotando as observações, desviaria a atenção das crianças sobre o material e/ou atividade.

Para manusear os materiais montessorianos, as crianças não receberam nenhum tipo de orientação. Elas iam explorando-os segundo sua criatividade e curiosidade.

Como na orientação montessoriana, as crianças foram deixadas à vontade no que se refere a sua acomodação na sala de atividades. A preferência das crianças foi sentar-se no chão.

Após o contato inicial, o trabalho foi executado em seis momentos, denominados de atividades, tendo cada uma delas objetivos e materiais específicos. Nas três primeiras atividades, foram utilizados apenas princípios montessorianos e nas outras três, além dos princípios, foram utilizados materiais montessorianos. Para a execução de cada atividade, foram destinadas dez sessões, com a duração de 30 minutos cada uma, totalizando 60 sessões.

As atividades, objetivos e materiais envolvidos no estudo encontram-se indicados no Quadro 1. 
Quadro 1 - Atividades, objetivos e materiais relacionados ao estudo

\begin{tabular}{|c|c|c|}
\hline Atividades & Objetivos & Materiais \\
\hline $\begin{array}{l}\text { Primeira: } \\
\text { Varrer o } \\
\text { chão }\end{array}$ & $\begin{array}{l}\text { Realizar movimentos adequados } \\
\text { à tarefa, abrangendo as diversas } \\
\text { partes do corpo: braços, mãos, } \\
\text { pernas, tronco e cabeça. } \\
\text { Demonstrar a coordenação viso- } \\
\text { motora. }\end{array}$ & $\begin{array}{l}\text { Uma vassoura infantil, com fios de } \\
\text { nylon, com cabo de } 60 \mathrm{~cm} \text {; uma pá } \\
\text { plástica; um cesto de lixo plástico; } \\
\text { pedaços de papéis (que são jogados ao } \\
\text { chão para serem varridos) e o chão da } \\
\text { sala de atividades. }\end{array}$ \\
\hline $\begin{array}{l}\text { Segunda: } \\
\text { Andar } \\
\text { sobre } \\
\text { a linha }\end{array}$ & $\begin{array}{l}\text { Realizar movimentos adequados à } \\
\text { tarefa, tais como: andar corretamente } \\
\text { sobre a linha, parar c andar, de } \\
\text { acordo com a "voz de comando", } \\
\text { ou seja, permanecer cm silêncio e } \\
\text { atento para ouvir, entender e } \\
\text { executar a ordem. }\end{array}$ & $\begin{array}{l}\text { Uma caixa de giz colorido; o piso da sala } \\
\text { de atividades (onde foi desenhada uma } \\
\text { elipse); uma bola colorida de borracha; } \\
\text { uma colher de sopa de material } \\
\text { inoxidável; uma fita cassete (contendo a } \\
\text { gravação de uma parte da Sinfonia } n^{\circ} 40 \text {, } \\
\text { de Mozart ). }\end{array}$ \\
\hline $\begin{array}{l}\text { Terceira: } \\
\text { Retirar } \\
\text { brinquedos } \\
\text { do saco } \\
\text { misterioso }\end{array}$ & $\begin{array}{l}\text { Apresentar senso de estereo- } \\
\text { gnosia, tato, concentração, } \\
\text { linguagem, nomeando os objetos; } \\
\text { classificar os objetos por categorias } \\
\text { (exemplo: materiais escolares, } \\
\text { objetos de cozinha, etc.) }\end{array}$ & $\begin{array}{l}\text { Um retalho de flanela de cor laranja, } \\
\text { medindo } 50 x 42 \mathrm{~cm} \text {, para confeccionar o } \\
\text { saco misterioso que contém } 20 \\
\text { brinquedos. A relação dos objetos é a } \\
\text { seguinte: duas fivelas de plástico (uma } \\
\text { laranja e outra rosa); três lápis pretos; } \\
\text { duas borrachas brancas pequenas; um } \\
\text { pente pequeno, branco; duas tiaras } \\
\text { brancas de plástico para crianças; dois } \\
\text { polinhos cilindricos de plástico branco; } \\
\text { duas caixas (uma de papelão colorido } \\
\text { medindo 9x9 cm, e outra, pequena, em } \\
\text { forma de coração, de cor bege no fundo e a } \\
\text { tampa transparente); dois caminhões } \\
\text { pequenos, basculantes (um com a } \\
\text { carrocería azul e a frente marrom, e outro, } \\
\text { com a carrocería vermelha e a frente } \\
\text { amarela); um joguinho para mantimentos } \\
\text { (constituído de quatro potinhos } \\
\text { cilíndricos, com tamanho decrescente, cor } \\
\text { laranja, com tampas brancas, cada um } \\
\text { trazendo uma etiqueta indicando sua } \\
\text { utilização, ou seja, arroz, feijão, açúcar e } \\
\text { café), uma mesa e duas cadeiras. }\end{array}$ \\
\hline \begin{tabular}{l}
\multicolumn{1}{c}{ Quarta: } \\
Manusear o \\
material \\
geométrico
\end{tabular} & $\begin{array}{l}\text { Apresentar o conceito de } \\
\text { tamanho, coordenação viso- } \\
\text { motora, conceito de proporção e } \\
\text { concentração nas atividades. }\end{array}$ & $\begin{array}{l}0 \text { material é todo de madeira azul, tendo } \\
\text { uma base quadrada, medindo } 14 \times 14 \mathrm{~cm} \text {, } \\
\text { sete bolas também de madeira azul, } \\
\text { cujos tamanhos vão decrescendo, todas } \\
\text { encaixadas em uma base de ferro, fixada } \\
\text { no centro da base quadrada. }\end{array}$ \\
\hline
\end{tabular}


(continuação)

\begin{tabular}{|l|l|l|}
\hline $\begin{array}{l}\text { Quinta: } \\
\text { Manusear } \\
\text { parte do } \\
\text { gabinete } \\
\text { geométrico }\end{array}$ & $\begin{array}{l}\text { Manusear figuras geométricas } \\
\text { semelhantes com tamanhos } \\
\text { diferentes, apresentar concen- } \\
\text { tração na atividade, identificar os } \\
\text { diferentes tamanhos da mesma } \\
\text { figura, encaixando-as nos seus } \\
\text { devidos lugares. }\end{array}$ & $\begin{array}{l}\text { Uma gaveta (formato bandeja) de } \\
\text { madeira, medindo 47x34 cm, contendo } \\
\text { seis bandejinhas de madeira cor creme, } \\
\text { medindo 15x 15 cm cada uma, dentro das } \\
\text { quais se encontram encaixadas seis } \\
\text { figuras geométricas confeccionadas em } \\
\text { madeira azul, com puxadores de plástico } \\
\text { verde. As formas das figuras são: cinco } \\
\text { círculos de tamanhos diferentes e uma } \\
\text { oval. }\end{array}$ \\
\hline $\begin{array}{l}\text { Sexta: } \\
\text { outra parte } \\
\text { do gabinete } \\
\text { geométrico }\end{array}$ & $\begin{array}{l}\text { Manusear figuras geométricas } \\
\text { diferentes e identificar essa } \\
\text { seus devidos lugares. }\end{array}$ & $\begin{array}{l}\text { Uma gaveta formato bandeja) de } \\
\text { madeira, medindo 47x34 cm, contendo } \\
\text { seis bandejinhas de madeira cor creme, } \\
\text { medindo 15x 15 cm cada uma, dentro das } \\
\text { quais se encontram encaixadas seis } \\
\text { figuras geométricas confeccionadas em } \\
\text { madeira azul, com puxadores de plástico } \\
\text { verde. As formas das figuras são: três } \\
\text { triângulos isósceles com tamanhos da } \\
\text { abertura do ângulo diferentes, um } \\
\text { triângulo escaleno, um trapézio e uma } \\
\text { oval. }\end{array}$ \\
\hline
\end{tabular}

Para fins de expressar os resultados, foram utilizadas categorias, construídas a partir dos registros das observações.

As categorias levantadas foram:

Exploração do objeto - quando a criança cheira o objeto, bate-o ou esfrega-o sobre a mesa, sobre seus braços, coloca-o no chão, arrasta-o, sacodeo e assopra-o.

Exploração do espaço - indica os comportamentos apresentados pela criança na atividade exploratória do espaço.

Utilização adequada do espaço - refere-se ao andar na linha de maneira correta.

Observação interessante - relaciona-se com o que a criança diz, associado à atividade que está desenvolvendo no momento.

Criatividade no uso do material - a criança utiliza o objeto de maneira diferente da correta, por exemplo: a) utiliza os suportes das figuras geométricas como esponja, pulseira, prato, bandeja; b) utiliza as carrocerías dos caminhões como pratos e os potes do jogo de mantimentos como copos ou panelas; e c) esfrega um suporte de peça geométrica sobre a mesa e utiliza-o como um disco. 
Utilização adequada do objeto - pode ser considerada pelo fato de a criança perceber para que serve e como deve ser utilizado o objeto. Ao manusear o material geométrico, o fato de a criança conseguir colocar os orifícios da bola na haste de ferro, mesmo sem considerar o tamanho das bolas, ela demonstra ter compreendido como utilizá-lo, apesar de ser de forma incorreta, no primeiro momento.

Utilização adequada do espaço - quando a criança percorre o espaço conforme a delimitação indicada.

Exploração e utilização adequada do objeto - quando a criança apresenta estes dois tipos de comportamentos ao mesmo tempo.

Finalmente, os resultados foram analisados e discutidos.

Quanto aos resultados, observou-se que os dados obtidos em relação às seis atividades, indicaram que houve aprendizagem.

O Gráfico 1 mostra a comparação entre o desempenho das três crianças nas seis atividades em relação à categoria exploração do objeto.

Pode-se constatar que houve uma freqüência maior nas duas primeiras atividades, comparando-as com as outras quatro subseqüentes.

\section{Gráfico 1 - Comparação entre o desempenho das três crianças nas seis atividades, em relação à categoria Exploração do objeto}

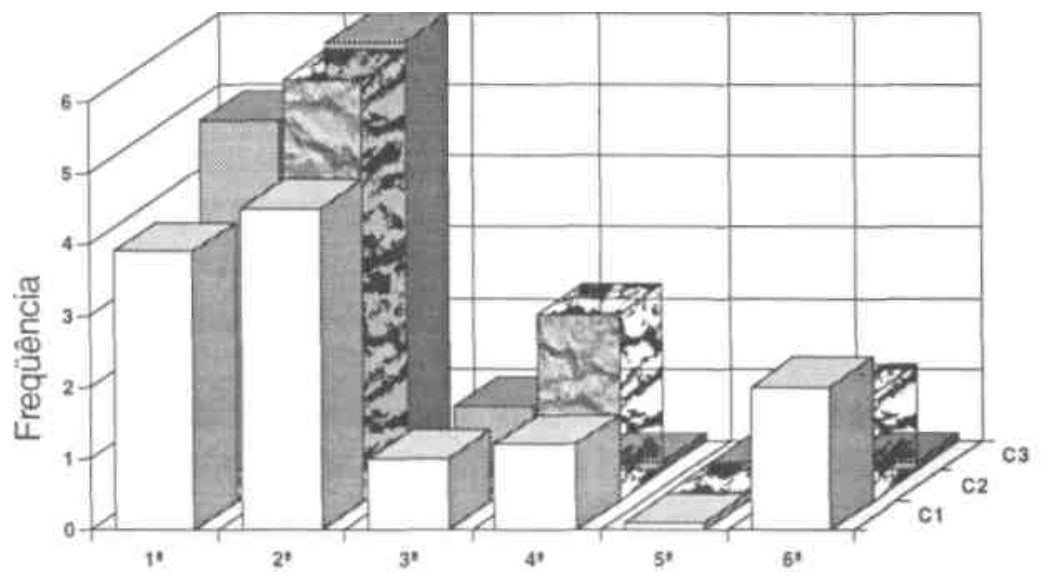

Atividades 
Já o Gráfico 2 mostra o gráfico comparativo entre o desempenho das três crianças, nas seis atividades em relação à categoria utilização adequada do objeto. Este gráfico apresenta uma espécie de inversão, se comparado ao Gráfico $1:$ aqui os dados mostram que as crianças deixaram de explorar o objeto e passaram a utilizá-lo adequadamente.

\section{Gráfico 2 - Comparação entre o desempenho das três crianças nas seis atividades, em relação à categoria Utilização adequada do objeto}

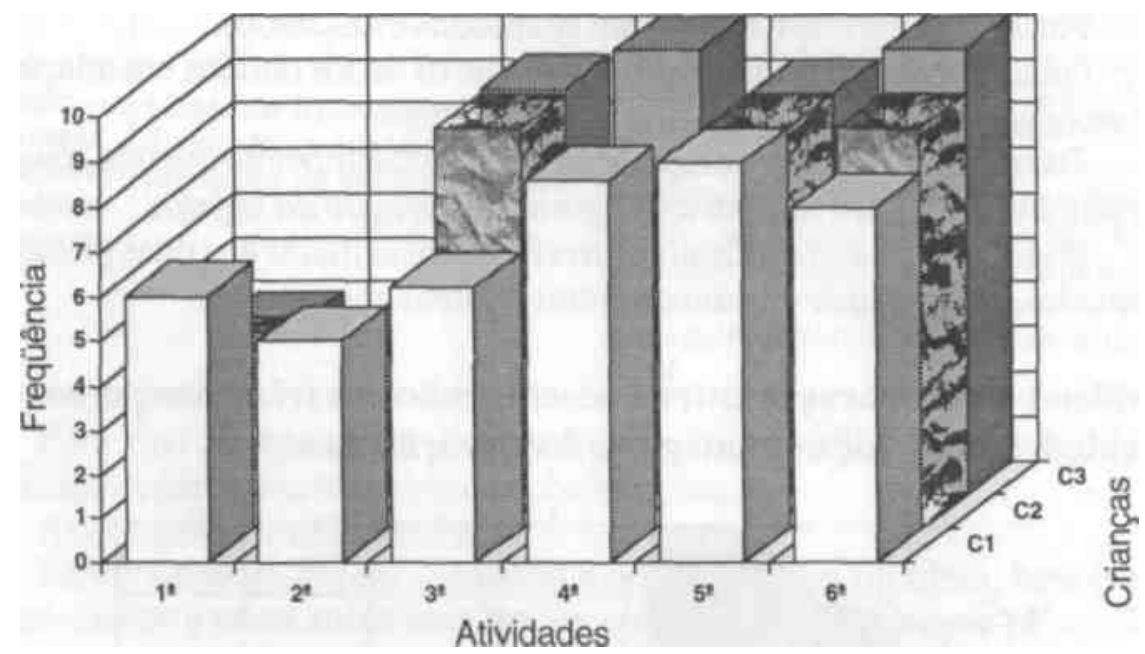

Pode-se inferir através destes dados indicados nestas duas figuras o seguinte: inicialmente as crianças se interessaram em explorar o objeto e à medida que foram aprendendo, passaram a utilizar adequadamente os objetos, ou seja, houve transferência de aprendizagem.

Discutindo os resultados, os dados permitem afirmar que o interesse, demonstrado pelas três crianças em explorar todos os materiais apresentados durante as sessões, foi uma constante. Constatou-se casos como, por exemplo, na atividade varrer o chão, a criança C2 apesar de já apresentar a utilização adequada do objeto, continuou explorando a vassoura sob outros aspectos 
como passá-la nas paredes, fazendo da vassoura cavalo. Isto nos remete a Montessori ( 1965) quando descreve o interesse da criança na exploração do material e na concentração desta durante o período que está em atividade, ou seja, ela permanece atenta e interessada no material que está explorando. Esse interesse e atenção, segundo Montessori (1987, p.69), ocorre porque "a criança tem um impulso vital de criar e de se aperfeiçoar". Observou-se no presente estudo que a criança portadora da síndrome de Down também apresenta o impulso de criar ao utilizar o objeto. Nesta criação passa também a aperfeiçoar sua utilização.

A atividade andar sobre a linha foi a em que as crianças apresentaram maiores dificuldades em realizá-la. Elas ocuparam grande parte do tempo das 10 sessões explorando o espaço, porque a realização adequada desta atividade (andar sobre uma linha demarcada no chão) exigia equilíbrio corporal, ou seja, uma coordenação geral mais "amadurecida". Provavelmente, uma pequena defasagem no equilíbrio corporal da criança portadora da síndrome de Down tomou a execução dessa tarefa com um grau de dificuldade maior, se comparada com as demais atividades.

Com relação à atividade retirar brinquedos do saco misterioso, as crianças tiveram várias oportunidades de expressar o seu pensamento sobre a atividade através da fala, demonstrando assim o aspecto cognitivo no que diz respeito à criatividade no uso do material. Elas criaram uma forma alternativa de utilizá-lo e diziam isso à experimentadora. Como exemplo pode ser mencionado a criança $C 2$, quando utilizou um pente como se fosse uma colher e afirmou que era uma colher.

A mesma criança, por sua vez, durante as sessões desta mesma atividade, simulou colocar alimentos dentro de um dos potes. Em seguida, colocou a tampa, e retirou-a dizendo o seguinte: "Vou fazer comida". Em seguida, fez barulho com a boca, simulando o som da panela quando o alimento está sendo cozido.

Na questão da inferencia, se houve aprendizagem no decorrer das sessões do presente estudo por parte das crianças, pode-se concluir afirmativamente. Assim, também, pode-se fazer um paralelo com Pessotti (1984), quando ele descreve que Itard no processo educativo de Victor, procurou observar o seu 
desenvolvimento cognitivo mediante os seus comportamentos, frente às atividades que lhes eram propostas (cujo trabalho serviu de base ao método montessoriano) como, por exemplo, aprender a vestir roupas adequadas com a temperatura ambiente.

A experimentadora deste trabalho também procurou observar, através de pequenos detalhes dos comportamentos das crianças, respostas ligadas ao aspecto cognitivo.

Nas três últimas atividades, foram notáveis as demonstrações que as crianças apresentaram: a resposta emitida ao identificar o caráter corretivo dos materiais, como por exemplo, quando a criança C3 ao perceber que a figura geométrica na quinta atividade não se encaixava adequadamente interrogou a experimentadora: "Por que não cabe?"

$\mathrm{Na}$ quinta atividade, as três crianças utilizaram peças deste material de forma diferente da adequada, entretanto de forma criativa, alternando com o uso adequado do material. A criança $C j$, por exemplo, utilizou um dos suportes de peças geométricas como pulseira; a criança $C$ utilizou uma figura geométrica (segurando-a pelo puxador) friccionando-a nos braços e rosto como se fosse esponja, e disse o seguinte: "É talco"; a criança $\mathrm{Cj}$, por sua vez, utilizou os citados suportes, conforme ela mesma disse: "Prato para comer carne"; "Prato para comer sopa" e "Prato de comida".

Durante o desenrolar das sessões, pode-se inferir que as crianças foram demonstrando entender a essência de cada tarefa, o que pode ser exteriorizado através de suas perguntas e maneiras de agir. Isso mostrou que a criança conseguiu abstrair essa essência. As respostas apresentadas pelas crianças nos levam a crer que elas reagiram frente aos materiais montessorianos, da mesma forma esperada em relação às crianças normais: com interesse, atenção e curiosidade.

Como foi visto, as respostas das crianças com síndrome de Down, frente aos princípios e ao material montessorianos, são similares às respostas da criança "normal". Neste caso, deduz-se que o método montessoriano pode ser utilizado para o ensino da criança portadora da síndrome de Down. 
Conforme Montessori (1965), o seu método também propicia que a criança desenvolva a linguagem oral. Este aspecto foi observado durante as sessões, quando na execução das atividades, as crianças tanto perguntavam como faziam afirmações sobre a utilização dos materiais.

Finalizando sobre a discussão dos resultados do presente estudo, vale ressaltar a colocação de Montessori que também pode ser aplicada à criança portadora da síndrome de Down:

\begin{abstract}
A criança não é um ser vazio, que deve a nós tudo aquilo que sabe. Não, a criança é o construtor do homem, não existe um só homem que não tenha sido formado pela criança que foi certo dia (Montessori, 1987, p.25).
\end{abstract}

\title{
Referências bibliográficas
}

ALVES, J.M. Estudo sobre a relação entre a extensão falada/escrita de palavras por crianças portadoras da síndrome de Down. São Carlos: Universidade Federal de São Carlos, 1987.

BALLABEN, M.C.G., FARIA, M.N.M., MONTEIRO, M.I.B. Construção do pensamento lógico por crianças com síndrome de Down. Revista Brasileira de Educação Especial, Piracicaba, v. 1, n.2, p. 17-29,1994.

BIRD, G. Number skill: the counting principles. Newsletter: Portsmounth Down's syndrome, v. 1, n. 10, dez. 1991.

BUCKLEY, S. Attaining basic educational skills: reading, writing and number. In: LANE, D., STRATFORD, B. Current approaches to Down's syndrome. Londres, Hold: [s.n.], 1985.p.315-330.

. Teaching reading to teach language to children with Dow's syndrome: outcomes and theorical significance. ASMD CONGRESS, 9, 1992, Austrália. [SI: s.n., 1992?]. 
CASEY, W., JONES, D., KUGLER, B., WATKINS, B. Integration of Down's syndrome children in the primary school: a longitudinal study of cognitive development and academic attainments. British Journal of Educational Psychology, Edinburgh, v.58, p.279-286,1988.

CASTRO, C.C. Síndrome de Down: um estudo realizado no Centro de Reabilitação de Pelotas. Pelotas: [s.n.], 1993.

FARIA, M.N.M. Alfabetização de crianças portadoras da síndrome de Down: analisando uma proposta de ensino. São Carlos: Universidade Federal de São Carlos, 1993.

LAGOA, V. Estudo do sistema Montessori: fundamentado na análise experimental do comportamento. São Paulo: Loyola, 1981.

LAMORÉA, M.L. O ensino de portadores da síndrome de Down através do método Montessori: análise do desempenho de três crianças em relação a seis atividades. São Carlos: Universidade Federal de São Carlos, 1995.

MONTESSORI, M. A criança. Lisboa: Portugália, [197-?].

. Ideas generales sobre mi método. Buenos Aires: Losada, 1957a.

. Mente absorvente. Rio de Janeiro: Nórdica, 1987.

. Pedagogia científica. São Paulo: Flamboyant, 1965.

. La scopeta del bambino. Milão: Garzanti, $1957 b$.

MORSS, J.R. Cognitive development in the Down's syndrome infant: slow or different?. British Journal of Educational Psychology, Edinburgh, v.53, p.40-47, 1983.

PESSOTTI, I. Deficiência mental: da superstição à ciência. São Paulo: Edusp, 1984. 
Maria da Piedade Resende da Costa e Maria Lúcia Lamoréa são professoras do Programa de Pós-Graduação em Educação Especial da Universidade Federal de São Carlos (UFSCar).

The objective of this study is to determine whether Montessorian principies and material can be successufully used with children suffering from Down's syndrome. Three children were subjected to six different types of Montessorian activity consisting of sixty sessions for each participant: success and failure in performing the tasks - that is, the way each child resolved a problem on being exposed to Montessorian material - were observed and registered. According to data analysis, each child showed ability and creativity, given his rhythm and repertoire, in handling the material. It was concluded that the Montessorian principles and material can be used for teaching children suffering from Down's syndrome.

Le but de ce travail a été I 'investigation de la possibilité d 'application des príncipes et matériaux de la méthode Montessori aux enfants qui présentent la syndrome de Down. Trois enfants présentant cette syndrome ont été exposés à six différents types d'activités proposées par la méthode Montessori. Chaque participant a totalisé 60 séances, pendant lesquelles on a enregistré les comportements des enfants face aux problèmes posés, leurs réussites et leurs erreurs. L'analyse des données a montré que chaque enfant a manifesté et habilité et capacité de création dans la manipulation des matériaux selon son rythme et niveau. Les résultats obtenus ont permis de conclure que les principes et le matériel de la méthode Montessori peuvent être utilisés avec succès dans Venseignement des enfants qui présentent la syndrome de Down.

El presente estudio tuvo por objetivo investigar si principios y material montessorianos podrían ser utilizados con éxito por niños portadores de síndrome de Down. Tres niños con este síndrome fueron expuestos a seis 
tipos diferentes de actividades montessorianas, completando 60 sesiones cada uno. Los comportamientos observados y registrados informaron aciertos y errores en la ejecución de las tareas, o sea, en la forma como cada niño resolvió el problema al ser expuesto a dicho material. Según el análisis de los datos, cada niño demonstró habilidad y creatividad en la manipulación del material de acuerdo con su ritmo y repertorio. Se concluyó que los principios y el material monte s Sorianos pueden ser utilizados para la enseñanza del niño portador de síndrome deDown. 